\title{
Farklı Salmonella Typhimurium kökenlerinin taşıdıkları patojenite adası ve direnç genlerinin İn Silico analizi
}

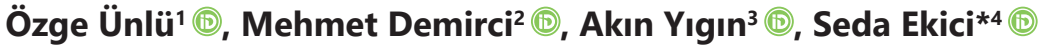 \\ ${ }^{1}$ İstanbul Atlas Üniversitesi Tıp Fakültesi, Tıbbi Mikrobiyoloji Anabilim Dalı, Istanbul, Türkiye. \\ ${ }^{2}$ Kırklareli Üniversitesi Tıp Fakültesi, Tıbbi Mikrobiyoloji Anabilim Dalı, Kırklareli, Türkiye. \\ ${ }^{3}$ Harran Üniversitesi, Veterinerlik Fakültesi, Genetik Anabilim Dalı, Sanliurfa, Türkiye. \\ ${ }^{4}$ Veteriner Kontrol Merkezi Araştırma Enstitüsü, Ankara, Turkiye.
}

Geliş Tarihi / Received: 01.07.2021, Kabul Tarihi / Accepted: 02.09.2021

\begin{abstract}
Özet: Salmonella typhimurium, dünyada en sık izole edilen Salmonella serotiplerinden birisidir. Tüm genom analizi gibi yeni moleküler yöntemlerin gelişmesi ile, antibiyotik direnci ve farklı genlerin karşılaştırmalı analizleri daha kolay yapılabilmektedir. Çalışmamızda farklı S. typhimurium kökenlerine ait genomik verilerin incelenmesi ile, taşıdıkları patojenite adaları, MLST tipleri, sekans serotipleri ve direnç genleri açısından karşılaştırmalı in silico analizini gerçekleştirmeyi amaçladık. Çalışmamıza genomik verileri NCBl'da yer alan 15 farklı S. typhimurium kökeni dahil edildi. Kökenlerin birbirleri ile evrimsel olarak yakınlıkları CSI filogeni, antimikrobiyal direnç belirteçlerinin varlığı ise ResFinder yazılımı ile gerçekleştirildi. Salmonella kökenlerine ait patojenite adaları, MLST ve sekans serotip tespiti için sırasıyla SPIFinder, MLST ve SeqSero yazılımları kullanıldı. Çalışmamıza dahil edilen 15 S. typhimurium kökeninin birbirlerine \%97 ve üstünde genomik benzerlik gösterdikleri tespit edildi. MLST analizlerine göre 9 köken (\%60) ST19 olarak bulundu. Tüm kökenlerin SPI-1, SPI-2, SPI-3, SPI-4, SPI-5, SPI-9, SPI-12, SPI-13, SPI-14 patojenite adalarını taşıdıkları gözlenirken, SGI1 patojenite adası sadece 3 kökende tespit edildi. Aminoglikozid direnci ile ilişkili aac(6')laa geni tüm kökenlerde saptandı. Yeni nesil dizileme tekniklerinin gelişimi, S. typhimurium gibi önemli enfeksiyon etkenlerine ait yeni moleküler epidemiyolojik veriler elde edilmesini sağlamaktadır. Bu verilerin karşılaştırmalı in silico analizleri ile enfeksiyonlarda kullandıkları virülans genlerinin analizleri ve moleküler patogenez mekanizmalarının aydınlatılması sağlanabilecektir.
\end{abstract}

Anahtar kelimeler: Direnç genleri, in silico analiz, Salmonella patojenite adası, Salmonella typhimurium.

\section{In Silico analysis of pathogenicity island and resistance genes carried by different Salmonella Typhimurium strains}

\begin{abstract}
Salmonella typhimurium is one of the most frequently isolated Salmonella serotypes in the world. With the path of the new strategy of analysis like whole genome, comparative analyzes of weakness and different genes can be done more easily. In our study, S. typhimurium has different origins, it is aimed for different purposes to analyze genomic data, calculus pathogens islands, belonging MLST, seqs types and silico genes. Our study included 15 different S. typhimurium strains whose local data were obtained in NCBI. Evolutionary affinities of origins with C. Pathogenicity islands of Salmonella origin, SPIFinder, MLST, and SeqSero software for MLST. It was determined that Typhimurium origins showed $97 \%$ and more genomic similarity. According to MLST analysis, origin 9 (60\%) was found to be ST19. While all were observed to carry pathogenicity islands SPI-1, SPI-2, SPI-3, SPI-4, SPI-5, SPI-9, SPI12 , SPI-13, SPI-14, only 3 were detected in SGI1 pathogenicity island. The aminoglycoside related aac $\left(6^{\prime}\right)$-laa gene was detected in all strains. It would seem that the course of sequencing techniques such as the next generation is to obtain a new epidemiological route for owners of S. Typhimurium. With these data comparative analyzes, virulence genes that can be applied and the analyzes that can be corrected can be elucidated.
\end{abstract}

Keywords: Resistance genes, in silico analysis, Salmonella pathogenicity island, Salmonella typhimurium.

\section{Giriş}

En yaygın zoonotik gıda kaynaklı enfeksiyonlardan birisi olan Salmonelloz, dünya çapında önemli bir halk sağlığı sorunudur (Bahramianfard ve ark. 2021). Salmonelloz etkeni olan Salmonella, Enterobacteriaceae ailesine ait Gram negatif bir bakteridir. Fekal-oral yolla yayılır ve kontamine su ve yiyecekler yoluyla bulaşabilir. Şu anda 2600'den fazla Salmonella serovarı tanımlanmıştır (Barilleau ve ark. 2021). Salmonella enterica'nın tifoid olmayan serovarları (NTS), dünya çapında gıda kaynaklı enfeksiyonların ve ishallerin önde gelen nedenleridir. NTS arasında, $S$. typhimurium, dünya çapında hastalardan en sık izole edilenlerden Salmonella serotiplerinden birisidir 
(Anderson ve Kendall 2017). İnsanlarda ve hayvanlarda S. typhimurium'un neden olduğu Salmonelloz vakaları enfeksiyon sonrası 24 saat içinde gelişen ateş, akut bağırsak iltihabı ve ishal ile karakterizedir (Gart ve ark. 2016). S. typhimurium neden olduğu enfeksiyonlar için aşı bulunmamaktadır ve antibiyotiklerle tedavi seçenekleri kısıtlıdır. Çünkü $S$. typhimurium kökenleri birçok antibiyotiğe karşı direnç geliştirebilmektedir (Anderson ve ark. 2021). Fenotipik antibiyotik testleri yanında son yıllarda tüm genom analizi (WGS) gibi yeni moleküler yöntemlerin gelişmesi ile antibiyotik dirençi ve farklı genlerin karşılaştırmalı analizleri daha kolay yapılabilmektedir (Barilleau ve ark. 2021; Lerminiaux ve ark. 2020). Bu yöntemler ile yapılabilecek karşılaştırmalı genomik analizler, bir türün tüm üyeleri tarafından paylaşılan genleri ve türler arasında değişken dağılımlara sahip genlerin ayrımını sağlayabilir. Horizontal gene transfer (HGT) bu paylaşıma neden olan esas yoldur. Gram negatif bakterilerde genomik veya patojenite adalarının HGT ile aktarımı gerçekleşebilir ve bu onlara yeni ekolojik işlevler, evrimsel sıçramalarını sağlayabilir. Hatta yeni konaklar kazanmasına yardım edebilir (Lerminiaux ve ark. 2020). Patojenite adalarının bakteri evrimini ve yeni konaklara adaptasyonunu en iyi anlatabilecek model patojen Salmonella'lardır. Bu cinste toplam 24 patojenite adası tanımlanmıştır, ancak bu adaların hepsinin virülans faktörlerini taşıdığı deneysel olarak doğrulanmamıștır (Hayward ve ark. 2014; Lerminiaux ve ark. 2020; Urrutia ve ark. 2014). Bizde bu çalışmamızda, tüm genom analizleri yapılarak genomik verileri açık veritabanlarında yer alan 15 farklı S. typhimurium kökeninin karşılaştırmalı in silico analizini gerçekleştirmeyi ve taşıdığı direnç genlerini incelemeyi amaçladık.

\section{Gereç ve Yöntem}

Çalışmamıza tüm genom analizleri yapılarak genomik verileri açık veritabanlarında yer alan 15 farklı S. typhimurium kökeni dahil edilmiştir. Bu kökenlere ait fasta dizileri NCBI (https://www.ncbi.nlm.nih. gov/) veritabanından indirilerek çalışmamızda in silico analizleri amacıyla kullanıldı. Karşılaştırmalı in silico genomik analiz için çalışmamıza dahil edilen kökenlere ait bilgiler Tablo 1'de verildi.

Kökenlerin birbirleri ile evrimsel olarak yakınlıkları CSI filogeni yazılımı ile (https://www.genomicepidemiology.org/) gerçekleştirildi (Kaas ve ark. 2014). Kökenlerde bulunan antimikrobiyal direnç belirteçlerinin varlığı ResFinder 4.1 online yazılımı kullanılarak tespit edildi (Bortolaia ve ark. 2020). Kökenlerin çoklu lokus dizi tiplendirmeleri MLST 2.0
(Multi-Locus Sequence Typing) online yazılımı ile gerçekleştirildi (Larsen ve ark. 2012). Salmonella kökenlerine ait patojenite adalarının tespiti için SPIFinder 2.0 online yazılımı kullanıldı (Roer ve ark. 2016). Kökenlerin dizi analizleri üstünden Kauffmann White şemasına göre serotipleri ( $\mathrm{O}$ antijen: $\mathrm{H} 1$ antijen: $\mathrm{H} 2$ antijen) SeqSero yazılımı kullanılarak tespit edildi (Zhang ve ark. 2015).

Tablo 1. Çalışmaya dahil edilen S. typhimurium kökenlerinin $\mathrm{NCBI}$ erişim numaraları.

\begin{tabular}{lcc}
\hline & NCBI numarası & $\begin{array}{c}\text { Salmonella enterica subsp. } \\
\text { enterica serovar Typhimurium }\end{array}$ \\
\hline 1 & AE006468.2 & LT2 \\
\hline 2 & CP001363.1 & 14028S \\
\hline 3 & CP009102.1 & ATCC 13311 \\
\hline 4 & CP012681.1 & 33676 \\
\hline 5 & CP014536.1 & CDC 2010K-1587 \\
\hline 7 & CP014965.1 & CDC 2011K-1702 \\
\hline 8 & CP014975.1 & CDC 2009K-1640 \\
\hline 9 & CP014979.2 & CDC H2662 \\
\hline 10 & CP014983.1 & CDC 2009K-2059 \\
\hline 11 & CP016385.1 & 13-931 \\
\hline 12 & CP024619.1 & BL10 \\
\hline 13 & CP034719.1 & RSE04 \\
\hline 14 & CP067091.1 & ER3625 \\
\hline 15 & CP067397.1 & LB5000 \\
\hline & & \\
\hline
\end{tabular}

\section{Bulgular}

Çalışmamıza dahil edilen 15 S. typhimurium kökeninin ATCC 13311 kökenine göre birbirlerine olan benzerlikleri incelendiğinde, S. typhimurium CDC 2011K-1702 kökeninin \%100 benzer olduğu görüldü. BL10 kökeni \%97.56'lık benzerlik oranı ile en uzak evrimsel benzerliğe sahip köken olarak tespit edildi (Tablo 2, Şekil 1).

Çalışmamıza dahil edilen kökenlerin dizi analizi üstünden Kauffmann White şemasına göre serotipleri (seqsero; $\mathrm{O}$ antijen: $\mathrm{H} 1$ antijen: $\mathrm{H} 2$ antijen) incelendiğinde, 4:i:1,2 tipi kökenlerin 13'ünde tespit edildi, 2 köken ise 4:b:e,n,x olarak bulundu (Tablo 2). MLST analizlerine göre $15 \mathrm{~S}$. typhimurium kökeninin 9'u (\%60) ST19 olarak tespit edilirken, 2 köken (\%13.3) ST8128 olarak tespit edildi. (Tablo 2). Kökenlerdeki antibiyotik direnç genleri ResFinder 4.1 programı ile incelendiğinde, tüm kökenlerde aminoglikozid direnci ile ilişkili aac(6')-laa geni tespit edildi (Tablo 2). SGI1 patojenite adası içeren kökenlerde, blaCARB-2, sul1 direnç genlerinin ortak ola- 
rak bulunduğu tespit edildi. S. typhimurium 33676 kökeninde aac $\left(6^{\prime}\right)$-laa geni yanında florokinolon direnci ile ilişkili gyrA geni bulunurken, SGI1 patojenite adası içeren 2 kökende aac( $\left.6^{\prime}\right)$-laa, blaCARB-2, sul1 genleri yanında, aadA2b, floR, tet(G) genleri tespit edildi. Sadece S. typhimurium ER3625 kökeninde aac(6')-laa yanında yine aminoglikozid direnci ile ilişkili aph(3')-Ila geni saptandı (Tablo 2).
Çalışmamıza dahil edilen kökenlerin taşıdıkları Salmonella patojenite adaları incelendiğinde, tüm kökenlerde SPI-1, SPI-2, SPI-3, SPI-4, SPI-5, SPI-9, SPI-12, SPI-13, SPI-14 patojenite adalarını taşıdıkları gözlendi. SGI1 patojenite adası sadece 3 kökende tespit edilirken, C63PI 10 kökende, CS54_island ise 14 kökende bulundu (Tablo 3).

Tablo 2. Çalışmaya dahil edilen kökenlerin benzerlik, SeqSero, MLST ve antibiyotik direnç genlerinin dağılımı.

\begin{tabular}{|c|c|c|c|c|c|}
\hline & $\begin{array}{l}\text { NCBI Accession } \\
\text { Numbers }\end{array}$ & Sequence Identitty & SeqSero & $\begin{array}{c}\text { MLST } \\
\text { Sequence Type }\end{array}$ & ResFinder \\
\hline 1 & AE006468.2 & 99.69 & $4: i: 1,2$ & 19 & $\operatorname{aac}\left(6^{\prime}\right)$-laa \\
\hline 2 & СР001363.1 & 99.26 & $4: i: 1,2$ & 19 & $\operatorname{aac}\left(6^{\prime}\right)-$ laa \\
\hline 3 & CP009102.1 & 100 & $4: i: 1,2$ & 2066 & $\operatorname{aac}\left(6^{\prime}\right)-$ laa \\
\hline 4 & CР012681.1 & 97.93 & $4: i: 1,2$ & 213 & aac(6')-laa, gyrA \\
\hline 5 & СР014536.1 & 99.92 & $4: i: 1,2$ & 302 & aac $\left(6^{\prime}\right)$-laa \\
\hline 6 & CP014965.1 & 98.77 & $4: i: 1,2$ & 19 & aac(6')-laa \\
\hline 7 & CP014967.1 & 100 & $4: i: 1,2$ & 19 & $\operatorname{aac}\left(6^{\prime}\right)-l a a$, blaCARB-2, sul1 \\
\hline 8 & СР014975.1 & 99.78 & $4: i: 1,2$ & 19 & $\begin{array}{c}\text { aadA2b, aac(6')-laa, blaCARB-2, sul1, } \\
\text { floR, tet(G) }\end{array}$ \\
\hline 9 & СР014979.2 & 99.6 & $4: i: 1,2$ & 19 & $\begin{array}{c}\text { aadA2b, aac(6')-laa, blaCARB-2, sul1, } \\
\text { floR, tet(G) }\end{array}$ \\
\hline 10 & СР014983.1 & 98.9 & $4: i: 1,2$ & 19 & aac(6')-laa \\
\hline 11 & CP016385.1 & 99.86 & $4: i: 1,2$ & 19 & $\operatorname{aac}\left(6^{\prime}\right)$-laa \\
\hline 12 & CP024619.1 & 97.56 & $4: i: 1,2$ & 36 & aac(6')-laa \\
\hline 13 & СР034719.1 & 99.22 & $4: i: 1,2$ & 19 & aac $\left(6^{\prime}\right)$-laa \\
\hline 14 & CP067091.1 & 98.97 & $4: b: e, n, x$ & 8128 & $\operatorname{aac}\left(6^{\prime}\right)-$ laa, aph(3')-Іıa \\
\hline 15 & СР067397.1 & 99.01 & 4:b:e,n,x & 8128 & $\operatorname{aac}\left(6^{\prime}\right)-\mathrm{laa}$ \\
\hline
\end{tabular}

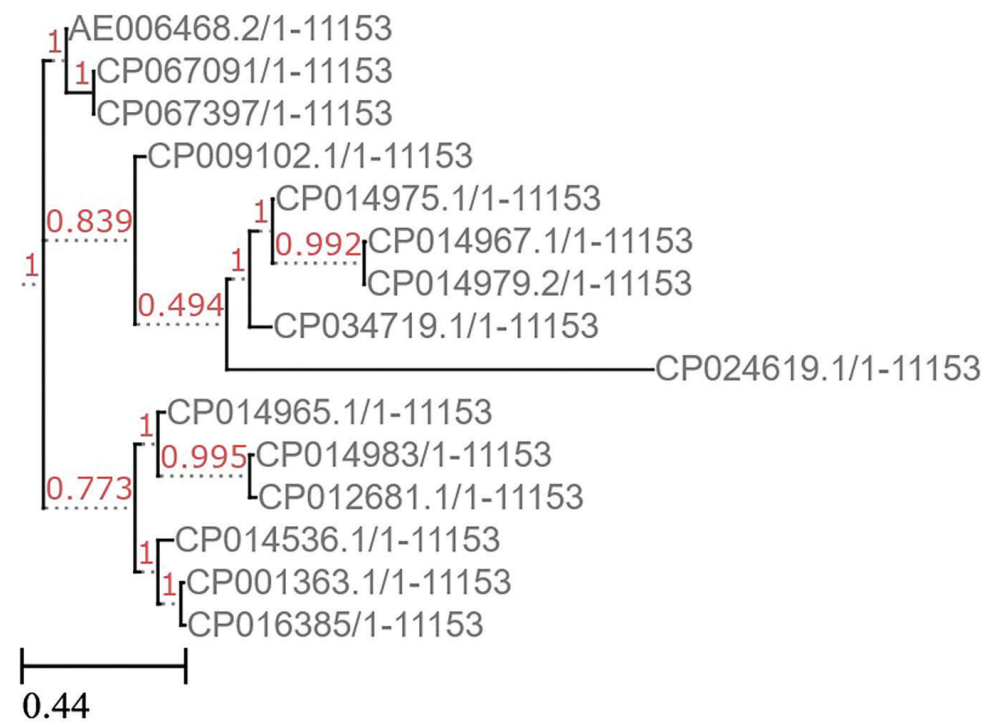

Şekil 1. Çalışmaya dahil edilen S. typhimurium kökenlerinin evrimsel ağaç analizi. 
Tablo 3. Çalışmaya dahil edilen kökenlerin taşıdıkları Salmonella patojenite adalarının dağııımı.

\begin{tabular}{|c|c|c|c|c|c|c|c|c|c|c|c|c|c|}
\hline & \multirow{2}{*}{$\begin{array}{c}\text { NCBI Erişim } \\
\text { numarası }\end{array}$} & \multicolumn{12}{|c|}{ Salmonella Patojenite Adaları } \\
\hline & & C63PI & $\begin{array}{l}\text { CS54 } \\
\text { island }\end{array}$ & SGI1 & SPI-1 & SPI-2 & SPI-3 & SPI-4 & SPI-5 & SPI-9 & SPI-12 & SPI-13 & SPI-14 \\
\hline 1 & AE006468.2 & & & & + & + & + & + & + & + & + & + & + \\
\hline 2 & СР001363.1 & & + & & + & + & + & + & + & + & + & + & + \\
\hline 3 & СР009102.1 & & + & & + & + & + & + & + & + & + & + & + \\
\hline 4 & СР012681.1 & + & + & & + & + & + & + & + & + & + & + & + \\
\hline 5 & СР014536.1 & & + & & + & + & + & + & + & + & + & + & + \\
\hline 6 & СР014965.1 & + & + & & + & + & + & + & + & + & + & + & + \\
\hline 7 & СР014967.1 & + & + & + & + & + & + & + & + & + & + & + & + \\
\hline 8 & СР014975.1 & + & + & + & + & + & + & + & + & + & + & + & + \\
\hline 9 & СР014979.2 & + & + & + & + & + & + & + & + & + & + & + & + \\
\hline 10 & CP014983.1 & + & + & & + & + & + & + & + & + & + & + & + \\
\hline 11 & СР016385.1 & & + & & + & + & + & + & + & + & + & + & + \\
\hline 12 & CP024619.1 & + & + & & + & + & + & + & + & + & + & + & + \\
\hline 13 & СР034719.1 & + & + & & + & + & + & + & + & + & + & + & + \\
\hline 14 & СР067091.1 & + & + & & + & + & + & + & + & + & + & + & + \\
\hline 15 & СР067397.1 & + & + & & + & + & + & + & + & + & + & + & + \\
\hline
\end{tabular}

\section{Tartışma ve Sonuç}

Salmonelloz morbidite ve mortalitede artışa sebep olan önemli bir halk sağlığı sorunudur. Salmonella türlerinin 2600'den fazla serotipi bulunmakta olup, bulaşları başlıca kontamine su ve gıdalar aracılığı ile fekal-oral yolla olmaktadır (Bahramianfard ve ark. 2021; Barilleau ve ark. 2021). Antimikrobiyal direnç paternleri serotipler arasında varyasyon göstermekte olup, S. enteritidis gastroenterit olgularından en fazla izole edilen serotip olmasına rağmen, ikinci en sık izole edilen serotip olan S. typhimurium daha fazla direnç geliștirme potansiyeline sahiptir (Unlu ve ark. 2018). Aynı zamanda bu serotipe ait kökenlerde 24 farklı patojenite adasının tanımlanmış olması, kökenlerin virulans potansiyelini ortaya koymaktadır (Hayward ve ark. 2014; Lerminiaux ve ark. 2020; Urrutia ve ark. 2014). S. typhimurium kökenlerinde artan antimikrobiyal direnç tedavi seçeneklerini sınırlandırmakta, kökenlerde gelişen direncin ve sahip olduğu patojenite adalarının monitorizasyonunu zorunlu kılmaktadır. Konvansiyonel antibiyotik duyarlılık testlerine ek olarak son yıllarda tüm genom analizi (WGS) gibi yeni moleküler yöntemlerin gelişmesi ile antibiyotik direnci ve farklı genlerin karşılaştırmalı analizleri daha kolay yapılabilmektedir (Barilleau ve ark. 2021; Lerminiaux ve ark. 2020). Biz de çalışmamızda, tüm genom analizleri yapılarak genomik verileri açık veritabanlarında yer alan 15 farkı S. typhimurium kökeninin karşılaştırmalı in sili- co analizini gerçekleştirmeyi ve taşıdığı direnç genlerini incelemeyi amaçladık.

Çalışmamız MLST analizlerine göre 15 S. typhimurium kökeninin 9'u (\%60) ST19 olarak tespit edildi. ST19 klonu tüm dünyada zoonotik gastroenterit etkeni olmakla birlikte, sistemik enfeksiyon potansiyeli ST313 gibi diğer klonlara kıyasla yüksek olmadığı bildirilmiştir (Carden ve ark. 2015). Ancak çalışmamıza dahil edilen örneklerden ST19 klonuna ait bir kökenin (Accession number: CP016385) kandan izole edilmiş olması klonun invazyon yeteneğini ortaya koymaktadır. Ayrıca ST19 klonu olarak saptanan üç ayrı kökende aminoglikozid direncinden sorumlu aac(6')-laa geni, karbenisilin direncinden sorumlu blaCARB-2 ve sulfonamid direncinden sorumlu sul1 geni birlikte saptandı. Monte ve ark. (2020) North Carolina'dan izole edilen beş ST19 kökeninin tümünde carbenicillinase [blaCARB-2], aminoglycosides $\left[a a c\left(6^{\prime}\right)\right.$-laa ve aadA2b], sulfonamide [sul1], tetracycline [tetG], ve florfenicol [floR] direncinden sorumlu genlerin birlikte bulunduğunu bildirmişlerdir. Bununla birlikte çalışmamızda tüm kökenlerde aac(6')-laa aminoglikozid direnç geni saptanmıştır. Rau ve ark. (2020) Brezilya Tarım bakanlığı, gıda kaynaklı patojenlerin kontrolü ulusal programı (Brazilian National Program for the Control of Foodborne Pathogens of Ministry of Agriculture) için topladıkları 490 Salmonella kökeninin sekizinde kolistin direncinden sorumlu mcr-1 genini saptamışlar ve bu geni taşıyan kökenlerin farklı antibiyotiklere 
de dirençli olduğunu saptamışlardır. Bu kökenlerde kolistin direncine ek olarak, yedi kökenin ampisiline, altı kökenin tetrasikline, ayrıca farklı beşer kökende nalidiksik asit, kloramfenikol, siprofloksasin ve gentamisine karşı direnç gösterdiklerini bildirmişlerdir. In silico analizler sonrası elde ettiğimiz sonuçlarımız literatürle uyumlu görülmektedir. S. typhimurium kökenlerinin çoklu dirence neden olabilen farklı direnç genlerini taşıdığı görülmüştür. Birbirlerine filogenetik açıdan benzer kökenlerin taşıdıkları genleri birbirlerine aktarabilecek yetenekte olmaları da bu kökenlerin genomik epidemiyolojik verilerinin takibini zorunlu kılmaktadır.

Birçok enterik patojenden farklı olarak tümü virulan kabul edilen Salmonella'lar doğaları gereği hastalık oluşturabilme yeteneğine sahiptir. Patojenin konağı invazyonu sürecinde "Salmonella Patojenite Adaları" olarak isimlendirilen farklı genetik lokuslar rol oynar. S. typhimurium kökenlerinde 24 farklı patojenite adasının tanımlanmıştır. SPI-1 ve PI-2 bunlardan en fazla çalışıımış olanlarıdır. SPI- 1 fagositoz yapmayan hücrelerin invazyonu ve gastrointestinal epitele penetrasyon gibi enfeksiyonun başlangıç evrelerinde etkili olurken, SPI-2 ise sistemik yayılım ve konak organlara kolonizasyon gibi enfeksiyonun daha geç safhalarında gereklidir. SGI1, ilk olarak epidemik S. typhimurium DT104 klonunda saptanmış olup, çoklu antibiyotik direnç genlerini (ACSSuT) taşıyan integronları içerirken, C63PI demir alım sistemi ile, CS54 island ise intestinal kolonizasyon ve persistans ile ilişkilidir (Hayward ve ark. 2014; Boyd ve ark. 2000; Patchanee ve ark. 2020). Boyd ve ark. (2000) ACSSuT tipi direnç paterninden (pentaresistance) sorumlu aadA2, floR, pse-1, sul1 ve tet(G) genlerinin, horizontal gen transferi ile ilişkili faj ve plazmid genlerini de taşıyan SGI-1'de kümelendiğini bildirmişlerdir. Patchanee ve ark. (2020) Tayvan Chiang Mai ve Lamphun bölgelerinde domuz üretim zincirlerinden 2011-2014 yılları arasında sekanslanan 19 S. typhimurium kökenlerini in silico analiz ettikleri çalışmalarında tüm kökenlerin ST34 klonuna ait olduğunu saptamışlardır. Aynı zamanda tüm kökenlerde aminoglikozid ve beta laktam direnç genleri bulunduğunu ve yine kökenlerin tümünün 7 patojenite adasını taşıdığını tespit etmişlerdir. llyas ve ark. (2017) derlemelerinde, horizontal gen transferinin S. typhimurium kökenleri için çok önemli olduğunu, bunun için SPI'ları kullandıklarını ve virülans genlerinin ufak değişimleri ile birçok hücre tipini enfekte edebileceğini ve çok şiddetli enfeksiyonlarla karşımıza çıkabileceğini belirtmişlerdir. İn silico olarak incelediğimiz S. typhimurium kökenlerinde 16 farklı patojenite adası saptadık. Tüm kökenlerde SPI-1, SPI-2, SPI-3, SPI-4, SPI-5, SPI-9, SPI-12, SPI-13, SPI-14 saptanırken, SGI1 sadece üç kökende, C63PI 10 kökende, CS54_island ise 14 kökende saptandı. SGI1 taşıyan kökenlerin literatüre paralel olarak çoklu ilaç direnci gösterdiği saptanmış olup, aac(6')-laa, blaCARB-2, sul1, aadA2b, floR, tet(G) direnç genleri bir arada tespit edildi. Illyas ve ark. (2017) belirttiği gibi, SPI-2, SPI-11, SPI-12, SPI-13 kökenlerin makrofajlarda yaşaması için gerekli patojenite adaları olarak görülmektedir. SPI-14'de SPI-1 genlerinin regülasyonu ve invazyon için gerekli görülmektedir. SPI-9'da farelerde yapılan çalışmalarda Salmonella kökenlerinde biyofilm oluşumu ile ilişkili virülans genleri için önemli olarak tespit edilmiştir (Velásquez ve ark. 2016). Tüm kökenlerde saptadığımız SPI'lar, bu görevleri dolayısıyla enfeksiyonlarda görev alması gereken virülans genlerini taşımaları açısından önemli olduğu görülmektedir ve literatürle uyumludur.

Tüm genom analizi verileri kullanılarak yapılan sekans serotip analizleri son yıllarda geliştirilmiştir ve birbirlerine filogenetik açıdan \%95 ve üstünde benzer kökenlerde oldukça başarılı olduğu antijenik serotipleme yerine genomik verilerle altın standart olarak kullanılabileceği gösterilmiştir (Banerji ve ark. 2020; Ibrahim ve ark. 2018). Bizde çalışmamızda kökenlerimizin WGS verilerini kullanılarak seqserotipleri tespit ettik. İncelediğimiz S. typhimurium kökenlerinde 2 farklı seqsero saptadık. Singh ve ark. (2021) Florida'da tüm Salmonella kökenleri üstüne yaptıkları analizde çalışmamız sonuçlarına benzer şekilde tek 4:i:1,2 seqserotipi saptadıklarını bildirmişlerdir. Yine bu çalışmada MLST analizlerinde ST19'u en yüksek sayıda saptadıklarını ve kökenlerin 65 'inin ST19 olarak olduğunu bildirmişlerdir. Yang ve ark. (2021) yılında çalışmalarında evcil köpeklerden elde ettikleri 5 S. typhimurium kökeninin 1'inin ST19 olduğunu bildirmişlerdir. Serotip ve MLST analizi sonuçlarımızın literatürle uyumlu olduğu görülmüştür.

Sonuç olarak çalışmamıza dahil 15 S. typhimurium kökenine ait genomik verilerin in silico analizi ile bu kökenlerde sabit SPI'ların taşındığı tespit edilmiştir. Farklı kökenler olmalarına karşın birbirlerine \%97 ve üstünde genomik benzerlik gösterdikleri tespit edildi. MLST analizinde ST19'un baskın olduğu bulundu. Yeni nesil dizileme tekniklerinin gelişimi, $S$. typhimurium gibi önemli etkenlere ait yeni moleküler epidemiyolojik veriler elde edilmesini sağlamaktadır. Bu verilerin karşılaştırmalı in silico analizleri ile enfeksiyonlarda kullandıkları virülans genlerinin analizleri ve moleküler patogenez mekanizmalarının aydınlatılması sağlanabilecektir. 
Çıkar Çatışması Bildirimi: Yazarların herhangi bir çıkar çatışması bulunmamaktadır.

Etik Bildirim: Çalışma etik ilke ve kuralları doğrultusunda gerçekleştirilmiştir.

\section{Kaynaklar}

Anderson C.J., Kendall M.M. (2017). Salmonella enterica Serovar Typhimurium Strategies for Host Adaptation. Front Microbiol. 2017;8:1983.

Anderson C. J., Medina, C. B., Barron, B. J., Karvelyte, L., Aaes, T. L., Lambertz, I., Ravichandran, K. S. (2021). Microbes exploit death-induced nutrient release by gut epithelial cells. Nature, $1-6$.

Bahramianfard H, Derakhshandeh A, Naziri Z, Khaltabadi Farahani R. (2021). Prevalence, virulence factor and antimicrobial resistance analysis of Salmonella Enteritidis from poultry and egg samples in Iran. BMC Vet ReS. 2021;17(1):196.

Banerji S, Simon S, Tille A, Fruth A, Flieger A.(2020). Genomebased Salmonella serotyping as the new gold standard. Sci Rep. 9;10(1):4333.

Barilleau E, Védrine $M$, Koczerka $M$, et al.(2021). Investigation of the invasion mechanism mediated by the outer membrane protein PagN of Salmonella Typhimurium. BMC Microbiol. 21(1):153.

Bortolaia V, Kaas RS, Ruppe E, Roberts MC, Schwarz S, Cattoir V, Philippon A, Allesoe RL, Rebelo AR, Florensa AF, Fagelhauer L, Chakraborty T, Neumann B, Werner G, Bender JK, Stingl K, Nguyen M, Coppens J, Xavier BB, Malhotra-Kumar S, Westh $H$, Pinholt M, Anjum MF, Duggett NA, Kempf I, Nykäsenoja S, Olkkola S, Wieczorek K, Amaro A, Clemente L, Mossong J, Losch S, Ragimbeau C, Lund O, Aarestrup FM. (2020). ResFinder 4.0 for predictions of phenotypes from genotypeS. J Antimicrob Chemother. 1;75(12):3491-3500.

Boyd, D.A., Peters, G.A., Ng, L.K., and Mulvey, M.R. (2000). Partial characterization of a genomic island associated with the multidrug resistance region of Salmonella enterica Typhimurium DT104. FEMS Microbiol Lett 189: 285- 291

Carden S, Okoro C, Dougan G, Monack D. (2015). Nontyphoidal Salmonella Typhimurium ST313 isolates that cause bacteremia in humans stimulate less inflammasome activation than ST19 isolates associated with gastroenteritiS. Pathog DiS. 73(4):ftu023.

Gart E.V., Suchodolski J.S., Welsh T.H. Jr, Alaniz R.C., Randel R.D., Lawhon S.D.(2016). Salmonella Typhimurium and Multidirectional Communication in the Gut. Front Microbiol. 2016:7:1827.

Hayward M.R., AbuOun M., La Ragione R.M., Tchórzewska M.A., Cooley W.A., Everest D.J., Petrovska L., Jansen V.A., Woodward M.J. (2014). SPI-23 of S. Derby: role in adherence and invasion of porcine tissueS. PLoS One. 19;9(9):e107857.

Ibrahim G.M., Morin P.M. (2018). Salmonella Serotyping Using Whole Genome Sequencing. Front Microbiol. 13;9:2993.

Ilyas B, Tsai CN, Coombes BK. (2017). Evolution of SalmonellaHost Cell Interactions through a Dynamic Bacterial Genome. Front Cell Infect Microbiol. 7:428.
Kaas RS, Leekitcharoenphon P, Aarestrup FM, Lund O.(2014) Solving the problem of comparing whole bacterial genomes across different sequencing platformS. PLoS One. 11;9(8):e104984.

Larsen MV, Cosentino S, Rasmussen S, Friis C, Hasman H, Marvig $\mathrm{RL}$, Jelsbak L, Sicheritz-Pontén T, Ussery DW, Aarestrup FM, Lund O. (2012). Multilocus sequence typing of total-genomesequenced bacteria. J Clin Microbiol. 2012;50(4):1355-61.

Lerminiaux NA, Mackenzie KD, Cameron ADS. (2020). Salmonella Pathogenicity Island 1 (SPI-1): The Evolution and Stabilization of a Core Genomic Type Three Secretion System. MicroorganismS. 8(4):576.

Monte DFM, Sellera FP, Lopes R, Keelara S, Landgraf M, Greene $S$, et al. (2020) Class 1 integron-borne cassettes harboring blaCARB-2 gene in multidrug-resistant and virulent Salmonella Typhimurium ST19 strains recovered from clinical human stool samples, United StateS. PLoS ONE 15 (10): e0240978.

Patchanee $\mathrm{P}$, Tanamai $\mathrm{P}$, Tadee $\mathrm{P}$, Hitchings MD, Calland JK, Sheppard SK, Meunsene D, Pascoe B, Tadee P. (2020). Wholegenome characterisation of multidrug resistant monophasic variants of Salmonella Typhimurium from pig production in Thailand. PeerJ 8:e9700

Rau RB, de Lima-Morales D, Wink PL, Ribeiro AR, Barth AL. (2020). Salmonella enterica mcr-1 Positive from Food in Brazil: Detection and Characterization. Foodborne Pathog DiS. 17(3):202-208.

Roer L, Hendriksen RS, Leekitcharoenphon P, Lukjancenko $O$ Kaas RS, Hasman H, Aarestrup FM.(2016). Is the Evolution of Salmonella enterica subsp. enterica Linked to RestrictionModification Systems? mSystemS. 2016;1(3):e00009-16.

Singh N, Li X, Beshearse E, Blanton JL, DeMent J, Havelaar AH.(2021). Molecular Epidemiology of Salmonellosis in Florida, USA, 2017-2018. Front Med (Lausanne). 8:656827.

Unlu O, Aktas Z, Tugrul HM.(2018). Analysis of Virulence Factors and Antimicrobial Resistance in Salmonella Using Molecular Techniques and Identification of Clonal Relationships Among the StrainS. Microb Drug Resist. 2018 Dec;24(10):1475-1482.

Urrutia IM, Fuentes JA, Valenzuela LM, Ortega AP, Hidalgo AA, Mora GC.(2014). Salmonella Typhi shdA: pseudogene or allelic variant? Infect Genet Evol. 2014;26:146-52.

Velásquez JC, Hidalgo AA, Villagra N, Santiviago CA, Mora GC, Fuentes JA.(2016). SPI-9 of Salmonella enterica serovar Typhi is constituted by an operon positively regulated by RpoS and contributes to adherence to epithelial cells in culture. Microbiology (Reading). 162(8):1367-1378

Zhang $S$, Yin $Y$, Jones $M B$, Zhang $Z$, Deatherage Kaiser $B L$, Dinsmore BA, Fitzgerald C, Fields PI, Deng X. (2015). Salmonella serotype determination utilizing high-throughput genome sequencing data. J Clin Microbiol. 53(5):1685-92.

Yang C, Shao W, Wei L, Chen L, Zhu A, Pan Z. (2021). Subtyping Salmonella isolated from pet dogs with multilocus sequence typing (MLST) and clustered regularly interspaced short palindromic repeats (CRISPRs). AMB ExpresS. 11(1):60 